\title{
Rancang Bangun Sistem Enterprise Resource Planning pada Modul Procurement Process (Purchasing) Berorientasikan Multi-Tenancy dengan Sistem Basis Data Terdistribusi
}

\author{
Muhammad Nicko Rahmadano, Riyanarto Sarno, dan Sarwosri \\ Jurusan Teknik Informatika, Fakultas Teknologi Informasi, Institut Teknologi Sepuluh Nopember (ITS) \\ Jl. Arief Rahman Hakim, Surabaya 60111 Indonesia \\ e-mail: sarwosri@if.its.ac.id, riyanarto@if.its.ac.id,nicko.rahmadano12@gmail.com
}

\begin{abstract}
Abstrak-Enterprise Resource Planning adalah sebuah sistem aplikasi yang digunakan untuk mengelola sebuah perusahaan besar yang dirancang untuk mengkoordinasikan semua sumber daya, informasi, dan aktifitas yang diperlukan untuk proses bisnis lengkap. ERP memiliki beberapa modul, salah satu modul yang penting dan yang telah dikerjakan pada tugas akhir ini yaitu Procurement Process atau Purchasing. Purchasing adalah suatu proses pengadaan barang pada perusahaan, Purchasing bertanggung jawab terutama pada pengurusan permintaan barang, pembelian barang, memonitor pembelian barang, dan pemilihan supplier. Dalam tugas akhir ini, dikembangkan aplikasi ERP yang dibangun dengan menggunakan sistem distributed database berorientasi multitenancy yaitu satu aplikasi dapat digunakan oleh beberapa perusahaan/tenant secara bersamaan dengan memisahkan database setiap tenant ke dalam computer/server tersendiri yang dibedakan oleh IP address setiap computer/server. Hal ini bertujuan untuk mencegah kegagalan sistem jika sebuah computer/server mengalami down, maka database masih bisa diakses oleh computer server lain. Pada modul Procurement Process dibuat sistem pembelian barang mulai dari permintaan pembelian barang (purchase requisition) sampai melakukan pembelian secara resmi (purchase order), dan menggunakan metode TOPSIS untuk menentukan supplier terbaik saat ingin membeli barang atau raw material berdasarkan dari transaksi pembelian yang telah terjadi sebelumnya. Hasil implementasi menunjukkan bahwa proses pembelian barang berhasil berjalan dengan baik dan benar. Untuk pemilihan supplier atau supplier analysis berhasil me-ranking supplier terbaik agar pembelian barang bisa berjalan dengan lancar.
\end{abstract}

Kata Kunci-procurement process, purchase order, purchase requisition, purchasing, supplier analysis, TOPSIS

\section{PENDAHULUAN}

$\mathrm{E}$ NTERPRISE Resource Planning adalah sebuah sistem yang digunakan untuk mengelola sebuah perusahaan besar yang dirancang untuk mengkoordinasikan semua sumber daya,informasi, dan aktifitas yang diperlukan untuk proses bisnis lengkap [1].

Pada saat ini ERP masih diimplementasikan oleh perusahaan-perusahaan besar saja, perusahaan-perusahaan kecil belum banyak yang menggunakan ERP karena penggunaanya dianggap terlalu merepotkan, oleh karena itu dibutuhkan sebuah service ERP yang bisa menyelesaikan masalah tersebut. Sistem ERP ini juga akan digunakan oleh banyak perusahaan, oleh karena itu diperlukan pendekatan Multi-Tenancy agar sistem ERP ini bisa digunakan oleh banyak perusahaan secara bersamaan.

Pada ERP terdapat banyak sekali modul-modul yang dibuat dan diintegrasikan, antara lain adalah Finance / Accounting, Sales and Delivery, Inventory, Production and Planning, Human Resource Management, Asset Management, Purchasing dan lainnya. Pada tugas akhir ini, dibangun suatu modul aplikasi Procurement Process.

Procurement Process atau proses pengadaan adalah sistem yang mengatur proses pengadaan barang dari inventory request sampai inventory and invoice receipt. Modul ini berfungsi agar pencatatan saat proses pengadaan barang lengkap dan benar, selain itu pada proses pengadaan barang banyak sekali terjadi kecurangan oleh karena itu dibutuhkan sistem pengadaan barang yang lengkap sehingga tidak terjadi kecurangan.

Pada pengembangan sebelumnya (aplikasi ERP 2013), dikembangkan sebuah program procurement pada domain supplier relationship management (SRM) yang tidak begitu befokus pada procurement process, pada domain SRM tidak ada sub modul yang membahas tentang request for Quotation, maintain Quotation, dan supplier analysis secara lengkap. Aplikasi tersebut menggunakan arsitektur berorientasi service (SOA) dengan sistem Model-View-Controller (MVC) dan Workflow untuk .NET [2].

Pada penelitian ini, lebih mendetailkan proses-proses pada pengadaaan barang (procurement). Modul Procurement Process dikembangkan untuk lebih mendetailkan proses-proses tersebut dimana meliputi submodul Purchase Requisition, Request for Quotation, Maintain Quotation, Purchase order, dan Supplier Analysis dengan orientasi basis data terdistribusi. Aplikasi ini menggunakan arsitektur multitenancy dengan sistem Model-View-Controller (MVC) dan Workflow untuk PHP menggunakan framework yii2 [1] [3].

Interaksi Modul Purchasing dengan modul-modul lainnya di dalam ERP digambarkan pada Gambar 1. Pada Gambar 1, dapat dilihat modul purchasing memiliki hubungan dengan modul Inventory and Warehouse Management dan dengan modul Account Payable.

Agar aplikasi ERP dapat digunakan oleh beberapa perusahaan secara bersama-sama maka diterapkan konsep Multitenancy [3]. Multitenancy dapat diterapkan melalui beberapa cara: 
1. Separated Database, setiap perusahaan memiliki basis data yang berbeda [2].

2. Shared Database, Separated Schema, setiap perusahaan memiliki table tersendiri pada basis data yang sama.

3. Shared Database, Shared Schema, masing-masing perusahaan saling berbagi table pada basis data yang sama.

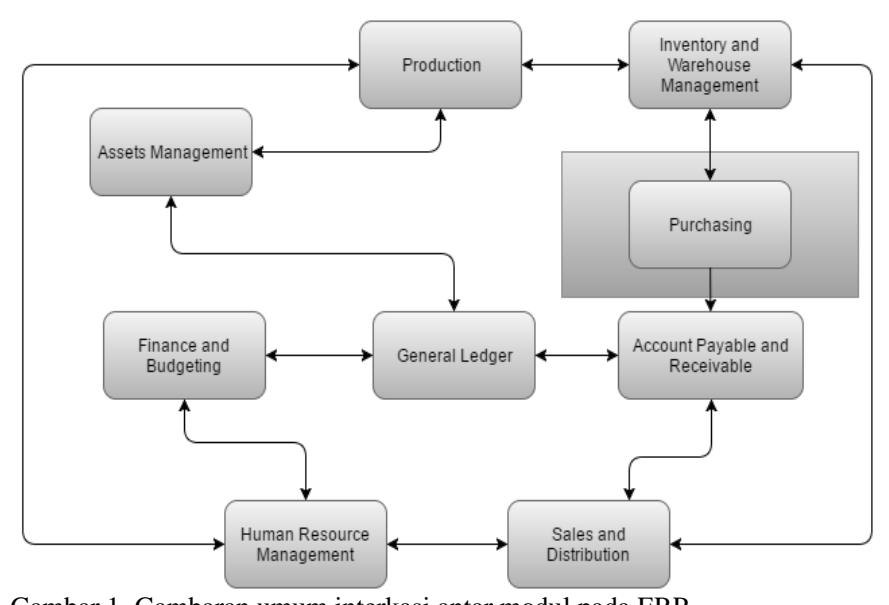

Gambar.1. Gambaran umum interkasi antar modul pada ERP

Mekanisme separated database dipilih karena mekanisme ini menjamin kerahasiaan data perusahaan. Alasan lainnya adalah tingkat kerumitan yang rendah pada saat pemeliharaan basis data. Mekanisme ini digambarkan pada Gambar 2.

Aspek non fungsional terakhir yang dapat mendukung tingkat ketersediaan aplikasi ERP adalah penerapan konsep Distributed Database. Konsep ini memungkinkan penyebaran table-table basis data baik secara replikasi maupun fragmentasi ke beberapa data node pada lokasi-lokasi yang tersebar. Replikasi adalah mekanisme penyalinan table-table baik struktur maupun data secara utuh ke seluruh data node. Sedangkan fragmentasi adalah pemecahan setiap table secara struktur maupun data lalu disebarkan ke seluruh data node. Mekanisme replikasi dipilih pada penelitian ini karena memiliki tingkat ketersediaan sistem (high availability) yang tinggi.

\section{TINJAUAN PUSTAKA}

\section{A. Penelitian Terkait (ERP 2013)}

Tugas Akhir ini merupakan pengembangan riset berkelanjutan dari riset atau penelitian tentang ERP. Pada pengembangan sebelumnya, telah dikembangkan aplikasi ERP yang diberi nama ERP 2013, aplikasi tersebut menggunakan Service Oriented Architecture (SOA) dengan sistem Model-ViewController (MVC) dan workflow untuk .NET, pada ERP tersebut terdapat modul yang sama seperti tugas akhir ini yaitu pada domain supplier chain management. Didalam modul tersebut, terdapat sub-modul purchase requisition dan purchase order tetapi tidak menangani permintaan Quotation, tidak menangani Quotation yang didapatkan dari supplier, dan tidak ada analisa terhadap supplier, pada ERP 2013 juga tidak terdapat laporan yang lengkap, yang berkaitan dengan pembelian. Pada tugas akhir ini menambahkan sub modul untuk mengelola Quotation yaitu request for Quotation dan maintain
Quotation, serta terdapat supplier analysis untuk mengevaluasi supplier berdasarkan transaksi-transaksi yang sudah terjadi sebelumnya, serta return order yang menangani pengembalian barang, dan pada ERP 2016 terdapat report-report lengkap yang berkaitan dengan pembelian barang.

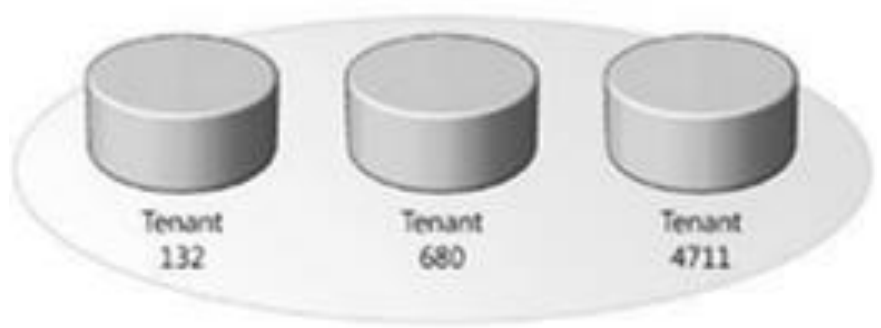

Gambar 2. Skema Multitenancy Separated Database

Tabel 1.

Perbandingan ERP2013 dan ERP2016

\begin{tabular}{|c|c|}
\hline ERP 2013 & ERP 2016 \\
\hline $\begin{array}{l}\text { Tidak ada fitur untuk mengelola } \\
\text { Quotation }\end{array}$ & $\begin{array}{l}\text { Terdapat fitur untuk m } \\
\text { Quotation yaitu pada Rea } \\
\text { Quotation dan Maintain } Q\end{array}$ \\
\hline lapat analisis supplier. & $\begin{array}{l}\text { bat analisis } \\
\text { kinig-an sup }\end{array}$ \\
\hline pat report yang b & $\begin{array}{l}\text { Terdapat report-report yang } \\
\text { berkaitan dengan pembelian. }\end{array}$ \\
\hline $\begin{array}{l}\text { Menggunakan Service Oriented } \\
\text { Architecture(SOA) }\end{array}$ & $\begin{array}{l}\text { Menggunakan } \\
\text { Database }\end{array}$ \\
\hline
\end{tabular}

\section{B. ERP (Enterprise Resource Planning)}

Enterprise Resource Planning (ERP) adalah sebuah aplikasi manajemen bisnis yang memudahkan pengelolaan bisnis secara terintegrasi [1]. Akhir-akhir ini perusahaan memperhitungkan ERP sebagai bagian penting dari suatu organisasi. ERP mengintegrasikan berbagai sistem informasi di dalam perusahaan. ERP mampu menyediakan informasi secara realtime tentang proses bisnis inti perusahaan seperti produksi, order processing, purchasing, dan inventory management. ERP memantau sumber daya perusahaan seperti uang, bahan mentah, kapasitas produksi, dan pegawai. ERP dipergunakan untuk mengelola status komitmen bisnis yang dibuat misalnya customer orders, purchase orders, and employee payroll. Dengan ERP data dapat dimasukkan ke dalam sistem dari berbagai departemen (manufacturing, purchasing, sales, accounting, dsb.) ERP mengelola data secara sentral sehingga hanya perlu sekali saja memasukkan data untuk selanjutnya dimanfaatkan oleh berbagai proses bisnis lainnya. ERP melancarkan arus informasi yang berjalan lintas fungsi di dalam organisasi sampai kepada hubungan dengan para stake holder di luar perusahaan.

\section{1) Procurement Process (Purchasing)}

Procurement Process merupakan proses yang mengatur sistem pengadaan barang dalam ERP. Procurement Process tidak hanya berfokus pada pembelian barang namun Procurement Process juga meliputi permintaan (requisition), meminta penawaran barang atau jasa yang dibutuhkan kepada pemasok sebagai penyedia barang dan jasa, menerima dan menyeleksi surat penawaran dari pemasok, dan menganalisa pemasok agar mendapatkan pemasok yang terbaik dalam pembelian barang [1]. 
Procurement Process meliputi pembuatan purchase requisition, request for Quotation, maintain Quotation, vendor atau supplier analysis, Purchase order, dan segala report mengenai purchasing. Proses bisnis level 1 pada modul purchasing terdapat pada Gambar 3.

\section{a) Purchase Requisition}

Purchase Requisition adalah sarana untuk membuat permintaan pembelian, agar pihak purchasing/buyer dapat melakukan proses pengadaan barang yang diminta. Purchase Requisition merupakan awal dari sebuah proses pengadaan barang. Barang yang diminta adalah barang yang terdaftar pada Item Master. Purchase Requisition berisi tentang jenis barang yang diminta, deskripsi atau detail barang yang diminta, dan tanggal barang tersebut dibutuhkan.

\section{b) Request for Quotation}

Request for Quotation (RfQ) adalah dokumen yang berisi permintaan penawaran secara resmi kepada supplier. RfQ atau yang lebih dikenal dengan surat permintaan penawaran berisi tentang detail barang yang diminta, jumlahnya, alamat pengiriman serta tanggal batas pengiriman Quotation. RfQ bertujuan untuk mendapatkan Quotation order atau surat penawaran dari supplier secara resmi.

\section{c) Quotation Order}

Quotation Order adalah surat penawaran barang yang diberikan oleh supplier, berisi tentang detail barang, harga barang, diskon, biaya pengiriman, dan pengeluaran untuk pajak. Quotation yang didapatkan dari supplier akan dianalisa oleh bagian purchasing dan menentukan apakah akan menerima atau menolak penawaran tersebut. Quotation order adalah patokan untuk membuat purchase order.

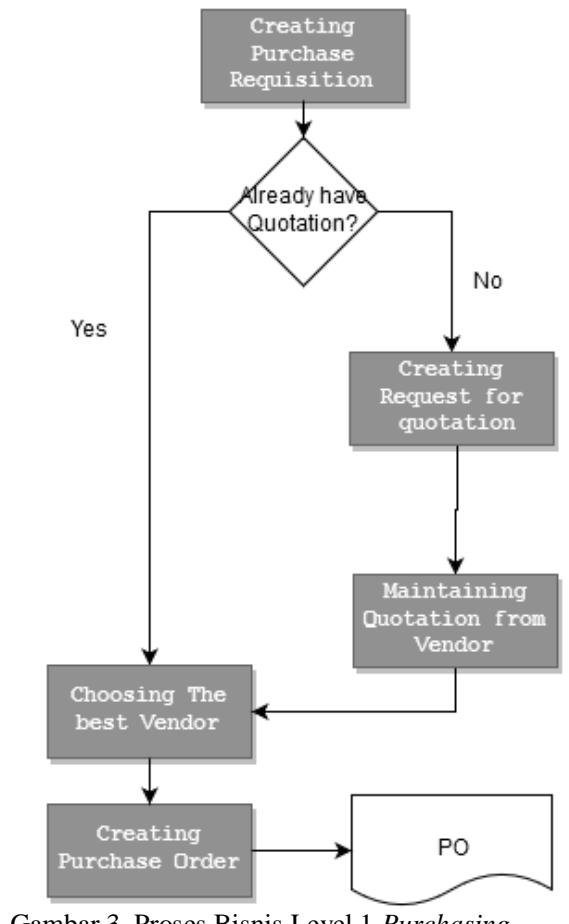

Gambar.3. Proses Bisnis Level 1 Purchasing

\section{d) Supplier Analysis}

Supplier Analysis adalah sebuah analisa untuk menentukan rekomendasi supplier untuk pembelian barang berdasarkan dari transaksi pembelian dan penerimaan barang yang telah dilakukan sebelumnya. Analisa ini bertujuan agar pihak purchasing tidak salah dalam memilih supplier dan mendapatkan barang dengan kualitas, dan harga yang terbaik.

\section{e) Purchase order}

Purchase order atau yang lebih dikenal dengan PO merupakan salah satu jenis surat binis yang sering ditemui. Saat purchasing melakukan order atau pemesanan kepada perusahaan rekanan atau supplier, purchasing wajib untuk mengirimkan baik via fax, -email, maupun pos. Surat ini akan digunakan supplier untuk mengetahui secara detail barangbarang apa saja yang dipesan. Ini berguna untuk mengatasi kesalahan dalam memproduksi pesanan. Selain itu, surat purchase order juga akan digunakan supplier (dan juga purchasing) sebagai file dan bagi bagian accounting/keuangan/pembukuan, surat purchase order ini akan dijadikan bukti transaksi laporan keuangan.

Di dalam Purchase order harus memuat dengan jelas jenis barang yang dipesan, jumlah yang dipesan, spesifikasi/permintaan khusus bila ada, tanggal pengiriman, serta yang tidak kalah pentingnya adalah harus mencantumkan nomer PO.

\section{TOPSIS}

Metode TOPSIS adalah salah satu metode pengambilan keputusan multikriteria yang pertama kali diperkenalkan oleh Yoon dan Hwang pada tahun 1981. Metode ini merupakan salah satu metode yang banyak digunakan untuk menyelesaikan pengambilan keputusan secara praktis. TOPSIS memiliki konsep dimana alternatif pada paper kali ini, alternatif yang dimaksud adalah supplier, yang terpilih merupakan alternatif terbaik yang memiliki jarak terpendek dari solusi ideal positif dan jarak terjauh dari solusi ideal negatif. Semakin banyaknya faktor yang harus dipertimbangkan dalam proses pengambilan keputusan, maka semakin relatif sulit juga untuk mengambil keputusan terhadap suatu permasalahan. Apalagi jika upaya peng ambilan keputusan dari suatu permasalahan tertentu, selain mempertimbangkan berbagai faktor/kriteria yang beragam, juga melibatkan beberapa orang pengambil keputusan. Permasalahan yang demikian dikenal dengan permasalahan multiple criteria decision making (MCDM). Dengan kata lain, MCDM juga dapat disebut sebagai suatu pengambilan keputusan untuk memilih alternatif terbaik dari sejumlah alternatif berdasarkan beberapa kriteria tertentu. Metode TOPSIS digunakan sebagai suatu upaya untuk menyelesaikan permasalahan multiple criteria decision making. Hal ini disebabkan konsepnya sederhana dan mudah dipahami, komputasinya efisien dan memiliki kemampuan untuk mengukur kinerja relatif dari alternatif-alternatif keputusan [4].

\section{1) Langkah-Langkah TOPSIS}

Langkah-langkah metode TOPSIS adalah sebagai berikut:

a. Menggambarkan alternatif (m) dan kriteria (n) kedalam sebuah matriks $\mathrm{x}_{\mathrm{ij}}$, dimana $\mathrm{x}_{\mathrm{ij}}$ adalah pengukuran pilihan dari alternatif ke-i dan kriteria ke-j. Matriks ini 
kemudian dinormalisasi $(\mathrm{R})$ dengan menghitung nilai $\mathrm{r}_{\mathrm{ij}}$ yang didapat dari (1).

$$
r_{i j}=\frac{\frac{1}{x_{i j}}}{\sqrt{\sum_{i=1}^{m} x_{i j}^{2}}}, i=1,2,3, \ldots, \mathrm{m} ; j=1,2,3, \ldots, \mathrm{n}
$$

b. Membuat pembobotan pada matriks yang telahdinormalisasi. Setelah dinormalisasi, setiap kolom pada matriks R (nilai $r_{i j}$ ) dikalikan dengan bobot $\left(w_{j}\right)$.

c. Menentukan nilai solusi ideal positif dan solusi ideal negatif. Solusi ideal positifdinotasikan $A^{*}$, sedangkan solusi ideal negatif dinotasikan $A^{*}$. Perhitungan untuk menentukan solusi ideal. Apabila pada suatu kriteria, alternatif yang memiliki nilai yang paling adalah yang paling baik, maka solusi ideal positif adalah nilai yang paling kecil tersebut.

d. Menentukan separation measure $\left(d_{i}\right)$. Separation measure ini merupakan pengukuran jarak dari suatu alternatif ke solusi ideal positif dan solusi ideal negatif. Jarak ke solusi ideal positif didapat dari (2) dan jarak ke solusi ideal negatif didapat dari (3).

$d_{i j}{ }^{*}=\sqrt{\sum_{j=1}^{n}\left(v_{i j}-v_{j}\right)^{2}}, i=1, \ldots, \mathrm{m}$

$d_{i j}{ }^{-}=\sqrt{\sum_{i=1}^{n}\left(v_{i j}-v_{j}\right)^{2}}, i=1, \ldots, \mathrm{m}$

e. Menghitung nilai preferensi $\left(\mathrm{CC}_{\mathrm{i}}\right)$ untuk setiap alternatif. Untuk menentukan ranking setiap alternatif yang ada maka perlu dihitung terlebih dahulu nilai preferensi dari tiap alternatif. Perhitungan nilai preferensi dapat dilihat melalui (4).

$$
C C_{i}=\frac{d_{i}^{-}}{d_{i} *+d_{i}^{-}}, I=1, \ldots, \mathrm{m}
$$

Setelah mendapatkan nilai $\mathrm{CC}_{\mathrm{i}}$, maka alternatif dapat diranking berdasarkan urutan $\mathrm{CC}_{\mathrm{i}}$. Dari hasil pe-ranking-an ini dapat dilihat alternatif terbaik yaitu alternatif yang memiliki jarak terpendek dari solusi ideal dan berjarak terjauh dari solusi ideal negatif. Nilai dari $\mathrm{CC}_{\mathrm{i}}$ adalah nilai akhir dari suatu alternatif. Alternatif yang memiliki nilai $\mathrm{CC}_{\mathrm{i}}$ paling tinggi adalah alternatif yang paling baik atau direkomendasikan.

\section{PERANCANGAN}

\section{A. Perancangan Supplier Analysis}

Pada analisa supplier terdapat istilah alternatif, dan kriteria, alternatif adalah supplier-supplier yang mau dianalisa, dan kriteria adalah data-data yang digunakan untuk mendapatkan score dari supplier. Ada tiga kriteria dalam menenukan supplier terbaik yaitu, harga barang, kualitas barang/jumlah barang cacat, dan lamanya keterlambatan dalam pengiriman, pemilihan tiga kriteria ini berdasarkan dari data-data transaksi yang telah ada sebelumnya yaitu dari data purchase order dan Good
Receipt. Data harga barang bisa didapatkan dari data pada purchase order. Data keterlambatan bisa didapatkan dari data pada Gr Documment Date di Good Receipt, dan data pada Need by Date di Purchase order, selisih dari kedua tangal itu akan dijadikan data keterlambatan. Data kualitas barang bisa didapatkan pada presentase item defect di Good Receipt. Algoritma atau langkah-langkah analisa supplier terdapat pada Gambar 3.

Dari tiga kriteria tersebut, terdapat empat bobot yang bisa dipilih, yaitu ignore atau diabaikan, not important atau tidak penting, important atau penting, dan very important atau sangat penting, keterangan pada setiap bobot terdapat pada Tabel 2 .

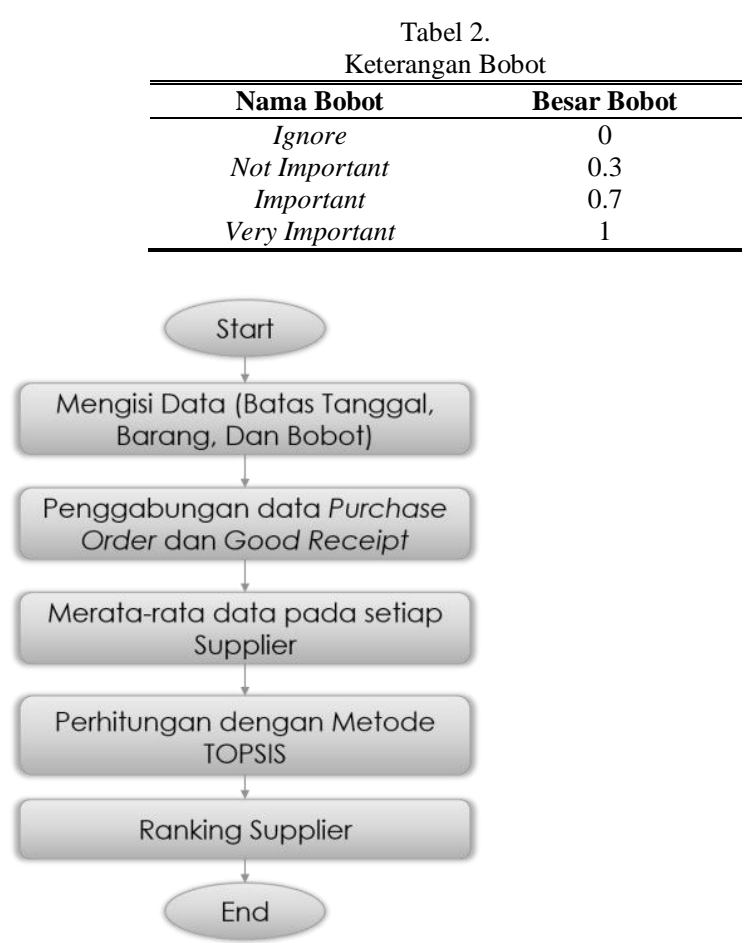

Gambar.3. Langkah-langkah Analisa Supplier

Data perbandingan antara Good Receipt dan Purchase order bisa dilihat pada Tabel 3 .

Tabel 3 .

\begin{tabular}{|c|c|c|c|c|c|c|c|}
\hline @ & : & $\cong$ & 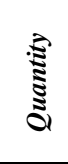 & $\stackrel{\Xi}{\Sigma}$ & 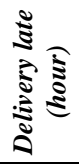 & 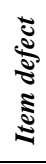 & 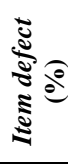 \\
\hline PO001 & $\begin{array}{l}\text { supplier } \\
\text { gear } 1\end{array}$ & gear & 200 & 20 & 2 & 2 & 1 \\
\hline PO002 & $\begin{array}{l}\text { supplier } \\
\text { gear } 1\end{array}$ & gear & 200 & 19 & 0 & 5 & 2.5 \\
\hline PO003 & $\begin{array}{l}\text { supplier } \\
\text { gear } 1\end{array}$ & gear & 200 & 18 & 4 & 13 & 6.5 \\
\hline PO004 & $\begin{array}{l}\text { supplier } \\
\text { gear } 2\end{array}$ & gear & 250 & 21 & 2 & 14 & 5.6 \\
\hline PO005 & $\begin{array}{l}\text { supplier } \\
\text { gear } 2\end{array}$ & gear & 200 & 20 & 6 & 12 & 6 \\
\hline
\end{tabular}

Gabungan Purchase order dan Good Receipt 


\begin{tabular}{|c|c|c|c|c|c|c|c|}
\hline$\stackrel{0}{2}$ & ڤ్ & $\stackrel{\Xi}{\Xi}$ & 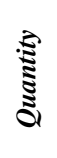 &. & 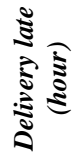 & 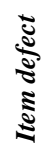 & 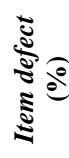 \\
\hline PO006 & $\begin{array}{l}\text { supplier } \\
\text { gear } 2\end{array}$ & gear & 150 & 18 & 3 & 17 & 11.33 \\
\hline PO007 & $\begin{array}{l}\text { supplier } \\
\text { gear } 3\end{array}$ & gear & 175 & 20 & 0 & 2 & 1.143 \\
\hline PO008 & $\begin{array}{l}\text { supplier } \\
\text { gear } 3\end{array}$ & gear & 200 & 20 & 5 & 9 & 4.5 \\
\hline PO009 & $\begin{array}{l}\text { supplier } \\
\text { gear } 3\end{array}$ & gear & 130 & 19 & 2 & 3 & 2.308 \\
\hline
\end{tabular}

Hasil dari analisa ini adalah sebuah ranking supplier, supplier yang memiliki nilai paling besar adalah supplier yang terbaik atau yang paling direkomendasikan. Contohnya terdapat pada Tabel 4.

Tabel 4.

Ranking Suppplier

\begin{tabular}{ccc}
\hline \hline Nama Supplier & $\mathbf{C C}_{\mathbf{i}}$ (Score) & Rank \\
\hline Supplier Gear 3 & 0.92 & 1 \\
Supplier Gear 1 & 0.88 & 2 \\
Supplier Gear 2 & 0.00 & 3 \\
\hline \hline
\end{tabular}

\section{B. Perancangan Multitenancy dan Distributed Database}

Konsep Multitenancy diterapkan beriringan dengan Distributed Database. Pada setiap data node yang menyusun Distributed Database akan memiliki jumlah database dan table yang sama dari setiap tenant yang ada. Selain itu, data node akan berhubungan langsung dengan web server untuk menjalankan operasi-operasi basis data. Rancangan Multitenancy dan Distributed Database tersebut dapat dilihat pada Gambar 4.

Sistem Distributed Database akan diatur secara terpusat oleh MySQL Server Cluster yang disebut management server. Server tersebut akan melakukan mekanisme replikasi baik table maupun data jika terdapat operasi basis data yang terjadi pada salah satu data node.

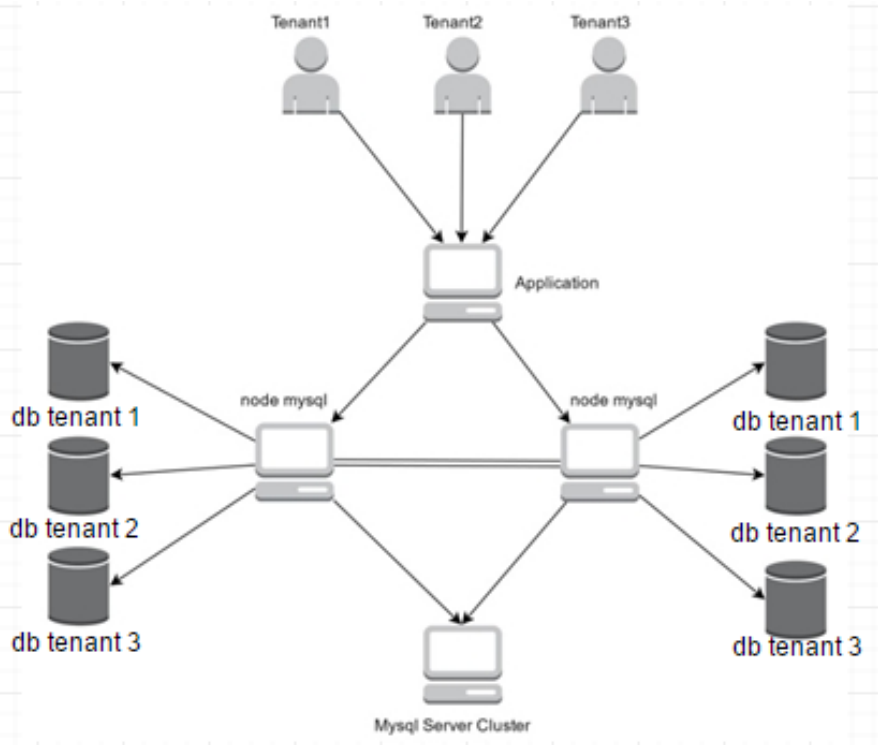

Gambar.4. Implementasi Multitenancy dan Distributed Database
Kegagalan pada sebuah data node tidak menyebabkan kegagalan sistem secara keseluruhan. Sebaliknya, management server akan melakukan pencatatan operasi basis data ke dalam sebuah log file. Sehingga, jika data node yang sebelumnya mangalami kegagalan kembali menyala maka management server akan melakukan operasi-operasi basis data pada node tersebut. Mekanisme sinkronisasi tersebut menyebabkan sistem memiliki tingkat ketersediaan yang tinggi (high availability).

\section{IMPLEMENTASI DAN EVALUASI}

Implementasi sistem merupakan hasil dari analisa setiap proses bisnis yang terlibat pada Modul Purchasing. Berikut contoh implementasi dari beberapa proses bisnis pada Modul Purchasing:

\section{A. Purchase order}

Hasil dari implementasi ini adalah sebuah dokumen pembelian barang (Purchase order) yang siap dikirimkan kepada supplier, dokumen purchase order berbentuk pdf. Hasil implementasinya terdapat pada Gambar 5.

\section{Company B Purchase Order}

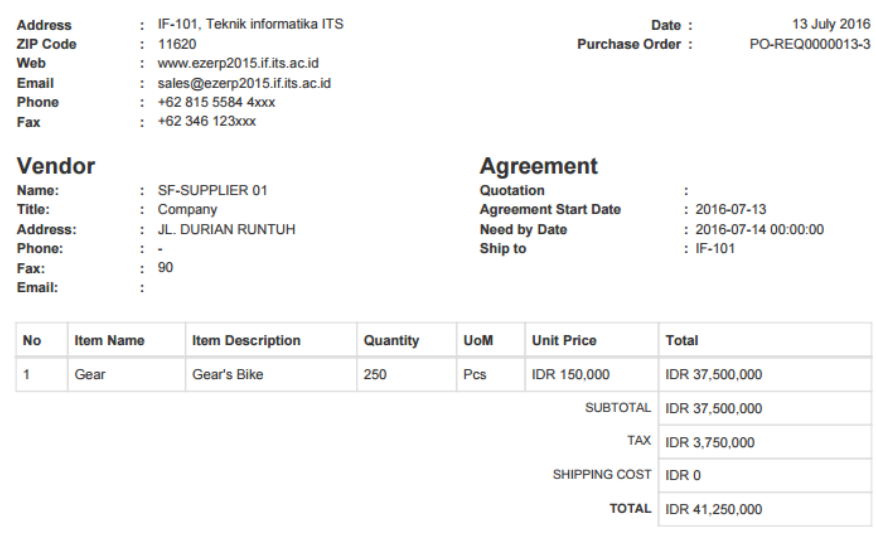

Gambar.5. Dokumen Purchase order

\section{B. Supplier Analysis}

Supplier Analysis yang ada pada aplikasi ERP, sudah berjalan dengan baik dan benar, perhitungan pe-ranking-an supplier yang dilakukan manual dengan Microsoft Excel memiliki hasil yang sama dengan perhitungan pe-ranking-an yang terdapat pada aplikasi ERP ini. Halaman pada supplier analysis pada aplikasi ini terdapat pada Gambar 6. Dihalaman itu terdapat pe-ranking-an supplier terbaik. Supplier yang memiliki rank nomer 1 adalah supplier yang paling direkomendasikan atau supplier yang terbaik.

\section{KESIMPULAN}

Berdasarkan hasil uji coba dan analisis, kesimpulan yang diperoleh dari hasil implementasi ini adalah sebagai berikut:

1. Aplikasi procurement process ini memudahkan pencatatan dalam pemesanan barang, dari permintaan barang sampai pemesanan barang secara resmi kepada supplier. 


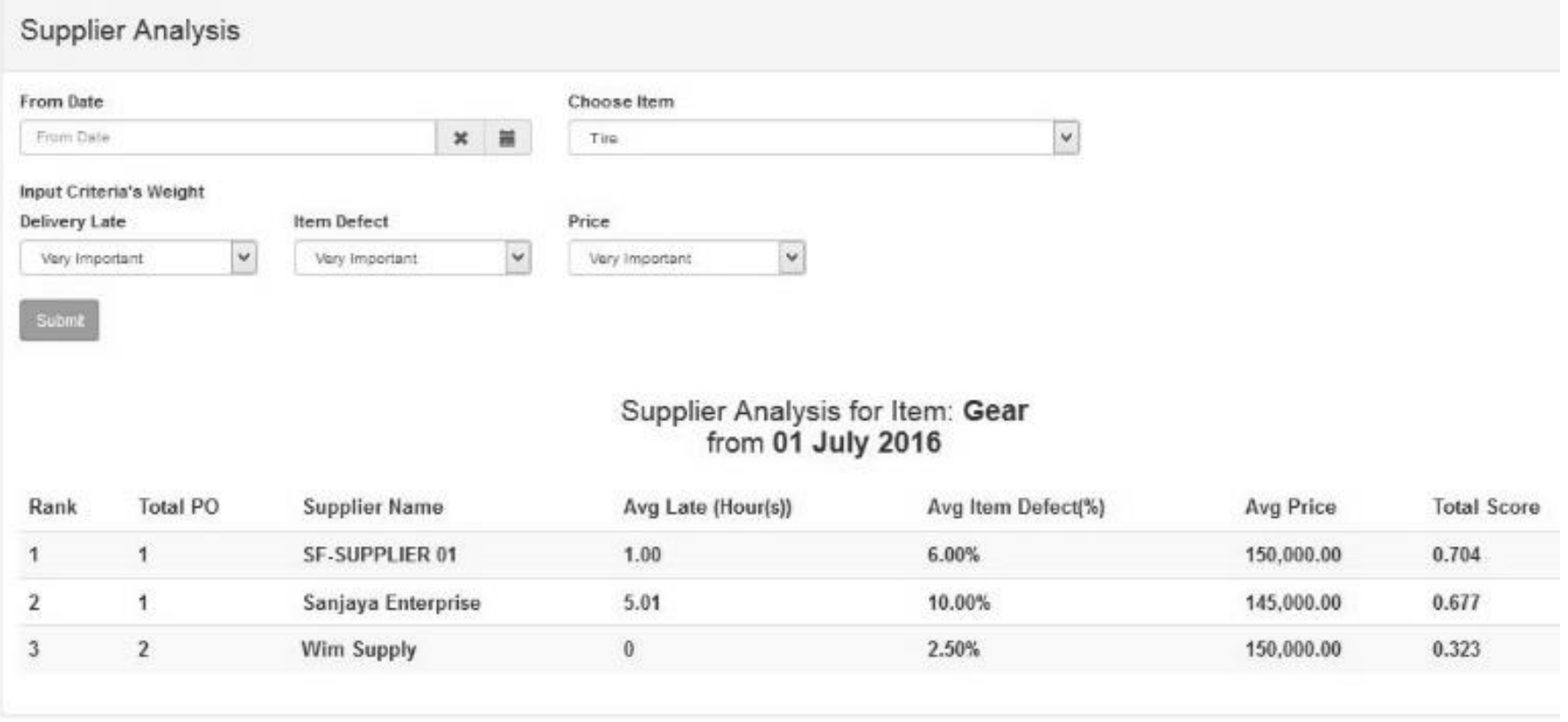

Gambar 6. Halaman Supplier Analysis

2. Metode TOPSIS berhasil digunakan untuk menentukan supplier terbaik dan me-ranking supplier.

3. Transaksi-transaksi pembelian yang sudah dilakukan sebelumnya seperti purchase order dan goods receipt bisa digunakan sebagai kriteria untuk menganalisa supplier.

4. Menggunakan lebih dari satu database server dan menggunakan teknik replikasi pada distributed database mampu mengatasi kegagalan sistem yang disebabkan oleh database server.

\section{DAFTAR PUSTAKA}

[1] S. R. Magal and J. Word, Integrated Business Processes with ERP Systems, New Jersey: Wiley and Sons, Inc., 2012.

[2] A. Rifa'i, R. Sarno and D. Sunaryono, Rancang Bangun Perangkat Lunak Berorientasi Arsitektur Service (SOA) Dengan Pendekatan Workflow Pada Domain Fungsional Supplier Relationship Management (SRM) Untuk Sistem Enterprise Resource Planning, Surabaya, 2013.

[3] Sharive, Proyek Membangun Website dengan Yii Framework, Yogyakarta: Lokomedia, 2014.

[4] F. Chong, G. Carraro and R. Wolter, "Multi-Tenant Data Architecture," 2006. [Online]. Available: https://msdn.microsoft.com/enus/library/aa479086.aspx. [Accessed 1 February 2016]. 